\title{
HOME SAFETY: DESAIN KEAMANAN GAS LPG DENGAN SENSOR PENDETEKSI KEBOCORAN
}

\author{
Cosmas Eko Suharyanto ${ }^{1}$, Andi Kesuma Harahap ${ }^{2}$, Alex Alfandianto ${ }^{3}$ \\ ${ }^{1,2}$ Fakultas Teknik dan Komputer Universitas Putera Batam \\ Jln. Let.Jend. Soeprapto, Tembesi, Kota Batam, Kepulauan Riau \\ ${ }^{3}$ Jurusan Teknik Industri, Universitas Teknologi Yogyakarta \\ Sendangadi, Kec. Mlati, Kabupaten Sleman, Daerah Istimewa Yogyakarta \\ E-mail : cosmas@puterabatam.ac.id, andikh@gmail.com, alexalfandianto@gmail.com
}

\begin{abstract}
Liquefied Petroleum Gas (LPG) is a diversion program undertaken by the government and become a modern household items today. LPG consists of a mixture of propane and butane which is a highly flammable chemical. This gas is an odorless gas, therefore, Ethanethiol is added as a strong aroma. The risk of the use of LPG is leakage of gas tube or gas hose. Gas leakage can couse explosion or fire resulting in many deaths and injuries. Governments have to disseminate the home safety of LPG and train how to mitigate household accident. This work aimed to minimize the possibility of fire and created a tool that is able to detect leakage of LPG using gas sensor and Arduino Uno. We create a mechanical design diagram as a model that illustrates the relationships between sub-systems. When the sensor detects the LPG gas, the system activates the relay and indicator lights. In addition, this tool can send SMS in case of leakage of gas, so that action can be done quickly to stop the gas flow. In the detection of LPG gas leaks, there is a priority point of leakage, so the greater the output voltage of the leaked gas sensor comes out, the faster the time required for SIM800L to send reports and turn off relays. Modul SIM800L makes this system more effective because SMS notifications can quickly become accurate information to get serious handling.
\end{abstract}

Keywords- LPG, gas leak, gas sensor, arduino

\begin{abstract}
ABSTRAK
Liquefied Petroleum Gas (LPG) adalah program pengalihan yang dilakukan oleh pemerintah dan menjadi barang rumah tangga modern saat ini. LPG terdiri dari campuran propana dan butana yang merupakan bahan kimia yang sangat mudah terbakar. Gas ini adalah gas yang tidak berbau, oleh karena itu, Ethanethiol ditambahkan sebagai aroma yang kuat. Risiko penggunaan LPG adalah kebocoran tabung gas atau selang gas. Kebocoran gas dapat menyebabkan ledakan atau kebakaran yang mengakibatkan banyak kematian dan cedera. Pemerintah harus memberikan sosialisasi tentang keselamatan LPG di rumah dan melatih cara mengurangi kecelakaan rumah tangga. Penelitian ini bertujuan untuk meminimalkan kemungkinan kebakaran dan menciptakan alat yang mampu mendeteksi kebocoran LPG menggunakan sensor gas dan Arduino Uno. Kami membuat Diagram rancangan mekanik sebagai model yang menggambarkan hubungan antar subsistem. Ketika sensor mendeteksi gas LPG, sistem mengaktifkan relai dan lampu indikator. Selain itu, alat ini dapat mengirim SMS jika terjadi kebocoran gas, sehingga tindakan dapat dilakukan dengan cepat untuk menghentikan aliran gas. Dalam pendeteksian kebocoran
\end{abstract}


gas LPG, ada titik kebocoran yang menjadi prioritas, sehingga semakin besar tegangan output sensor gas yang bocor itu keluar, maka semakin cepat waktu yang dibutuhkan SIM800L untuk mengirim laporan dan mematikan relay. Dengan modul SIM800L, sistem ini lebih efektif karena notifikasi SMS dengan cepat dapat menjadi informasi yang akurat untuk mendapatkan penanganan yang serius.

Kata Kunci-3-5 LPG, kebocoran gas, Sensor gas, arduino

\section{Pendahuluan}

LPG adalah sumber energi luar biasa yang dapat digunakan dalam berbagai aplikasi. LPG terbagi dalam dua proses asal : sekitar $60 \%$ diambil selama ekstraksi gas alam dan minyak dari bumi, dan $40 \%$ sisanya diproduksi selama penyulingan minyak mentah [1].

Kebocoran gas telah menjadi penyebab yang sangat membahayakan bagi keselamatan. Banyak kecelakaan kebakaran di hotel, restoran, dan rumahrumah disebabkan oleh kebocoran gas LPG. Meskipun kebocoran dapat dideteksi oleh aroma gas, namun tentu saja hal ini bukanlah cara yang efisien untuk menekan angka kecelakaan akibat kebocoran gas. Walaupun Pertamina sebagai pihak yang diberikan wewenang pendistribusian LPG menyatakan bahwa kecelakaan akibat gas LPG turun dari tahun ke tahun, namun upaya preventif harus tetap dilakukan, mengingat distribusi LPG juga terus mengalami kenaikan yang signifikan [2].

Banyak hal yang menyebabkan tejadinya kecelakaan akibat gas LPG, namun yang paling banyak adalah adanya kebocoran gas [3], [4]. Berdasarkan Badan Perlindungan Konsumen Nasional (BPKN) adalah sampai Juni 2010 terjadi 33 kasus, 8 orang meninggal dan 44 orang luka-luka. Tahun 2009 terjadi 30 kasus, 12 orang meninggal dan 48 oarng lukaluka. Tahun 2008 terjadi 27 kasus, 2 orang meninggal dan 35 oarng luka-luka. Dan tahun 2007 saat program konversi energi ini dimulai terjadi 5 kasus dan mengakibatkan 4 orang luka-luka [5]. Walaupun Pertamina telah mengklaim terjadinya penurunan kecelakaan akibat kebocoran LPG akhir-akhir ini [6], namun potensi itu ada karena kandungan LPG yang memang mudah terbakar. LPG terdiri dari campuran propana dan butana yang merupakan bahan kimia yang sangat mudah terbakar. Gas ini adalah gas yang tidak berbau, oleh karena itu, Ethanethiol ditambahkan sebagai aroma yang kuat, sehingga kebocoran dapat dengan mudah dideteksi [7], [8].

Penelitian ini bertujuan untuk meminimalkan kemungkinan kebakaran dan menciptakan alat yang mampu mendeteksi kebocoran LPG menggunakan sensor gas dan Arduino Uno. Ketika 
sensor mendeteksi gas LPG, sistem mengaktifkan relai dan lampu indikator. Selain itu, alat ini dapat mengirim SMS jika terjadi kebocoran gas, sehingga tindakan dapat dilakukan dengan cepat untuk menghentikan aliran gas.

Kami memodifikasi penelitian sebelumnya yang telah dilakukan [9]. Pada penelitian tersebut sistem lebih cocok diimplementasikan pada stasiun pengisian LPG, sedangkan pada penelitian ini, kami mendesain sistem agar lebih sederhana diimplementasikan untuk rumah tangga.

\section{Metode Penelitian}

Gambaran umum sistem terdiri dari diagram rancangan mekanik yang mencakup mikrokontroler, sensor gas, relay, modul GSM. Kami membuat Diagram rancangan mekanik (Gambar 1) sebagai model yang menggambarkan hubungan antar sub-sistem.

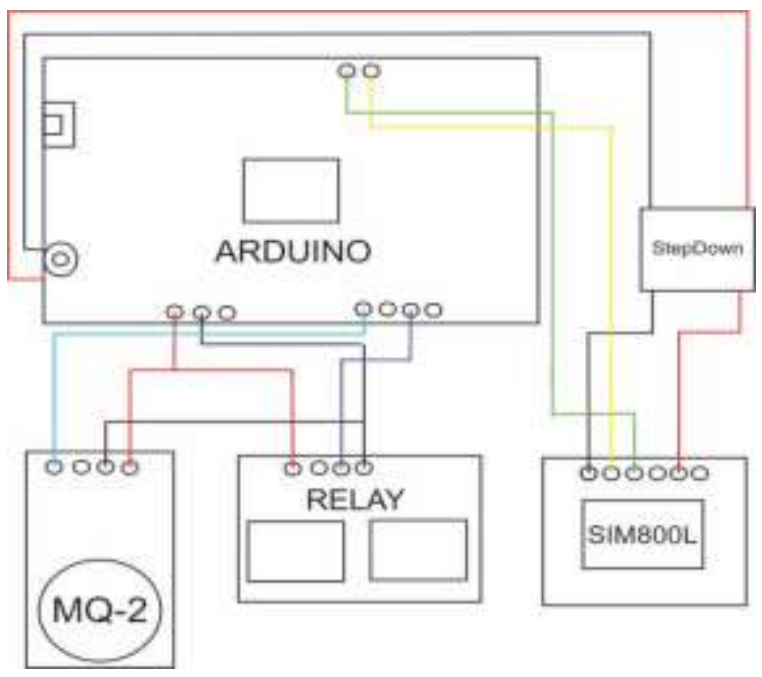

Gambar 1. Diagram rancangan mekanik
Sebagaimana terlihat dalam rancangan pada Gambar 1, sistem akan mendeteksi gas melalui sensor MQ-2, jika kadar gas di atas 50\%, maka sistem akan mengirim alert melalui pesan SMS.

Dalam penelitian ini, rancangan membutuhkan perangkat hardware dengan spesifikasi sebagaimana terlihat dalam Tabel 1, sebagai berikut:

Tabel 1. Spesifikasi Hardware

\begin{tabular}{|l|l|}
$\begin{array}{l}\text { Perangkat } \\
\text { Keras }\end{array}$ & \multicolumn{2}{l}{ Spesifikasi } \\
\hline Leptop (kerja) & $\begin{array}{l}\text { Asus X552L intel core i5 } \\
\text { 4200U @2.30Ghz, 12GB of } \\
\text { RAM, NVIDIA 820M 7GB } \\
\text { Total Memory, 500GB of } \\
\text { Hardisk. }\end{array}$ \\
\hline Arduino Uno & $\begin{array}{l}\text { Mikrokontroler Atmega 328, } \\
\text { memory flash 32KB, SRAM } \\
\text { 2KB, EEPROM 1KB, 16MHz } \\
\text { of clock }\end{array}$ \\
\hline Sensor MQ-2 & $\begin{array}{l}\text { Tegangan input 5VDC, Analog } \\
\text { Interface }\end{array}$ \\
\hline $\begin{array}{l}\text { Modul GSM } \\
\text { SIM800L }\end{array}$ & $\begin{array}{l}\text { Tegangan input 4,2VDC, } \\
\text { Frekuensi Quadband } \\
\text { 850/900/1800/1900Mhz. }\end{array}$ \\
\hline Relay & 2 chanel \\
\hline $\begin{array}{l}\text { Regulator } \\
\text { Stepdown } \\
\text { converter }\end{array}$ & $\begin{array}{l}\text { Input 5-28VDC, Output 3- } \\
\text { 20VDC }\end{array}$ \\
\hline Kabel & Kabel Jumper, kabel USB \\
\hline
\end{tabular}

\section{1 Microcontroller}

Teknik kontrol berkaitan dengan mengendalikan sistem dinamis maupun mesin industri. Sistem dinamis dapat berupa sistem mekanis, sistem kelistrikan, sistem fluida, sistem termal, atau kombinasi dari dua atau lebih tipe sistem. Perilaku sistem dinamis dijelaskan oleh persamaan diferensial. Mengingat model (persamaan diferensial), input dan kondisi 
awal, kita dapat dengan mudah menghitung output sistem [10].

Mikrokontroler berbeda dari mikroprosesor dalam banyak hal. Misalnya, mikroprosesor biasanya memiliki CPU yang membutuhkan komponen eksternal tertentu (mis. Memori, kontrol input, dan kontrol output) agar berfungsi dengan baik [11]. Mikroprosesor biasa dapat mengakses dari satu megabyte ke satu gigabyte memori, dan mampu memproses 16, 32, atau 64 bit informasi atau lebih dengan satu instruksi. Berbeda dengan mikroprosesor, mikrokontroler mencakup CPU, memori, dan elemen fungsional lainnya, semua pada Substrat Semikonduktor tunggal, atau sirkuit terpadu (mis., "Chip") [12].

Kontroler pertama yang digunakan secara luas adalah Intel 8048, yang diintegrasikan ke dalam keyboard PC, dan penggantinya, Intel 8051, serta seri mikrokontroler $68 \mathrm{HCxx}$ dari Motorola [13].

ATmega-328 pada dasarnya adalah mikro-controller Advanced Virtual RISC (AVR). Ini mendukung data hingga delapan (8) bit. ATmega-328 memiliki memori internal 32KB. Sebagaimana terlihat di Gambar 2, kontroler mikro ini memiliki banyak karakteristik lain. Atmega-328 memiliki Electrically Erasable Programmable Read Only
Memory (EEPROM) (EEPROM) $1 \mathrm{~KB}$. Properti ini menunjukkan jika pasokan listrik yang dipasok ke mikrokontroller dilepas, bahkan kemudian dapat menyimpan data dan dapat memberikan hasil setelah ketersediaan pasokan listrik. Apalagi ATmega-328 memiliki 2KB Static Random Access Memory (SRAM) [14].

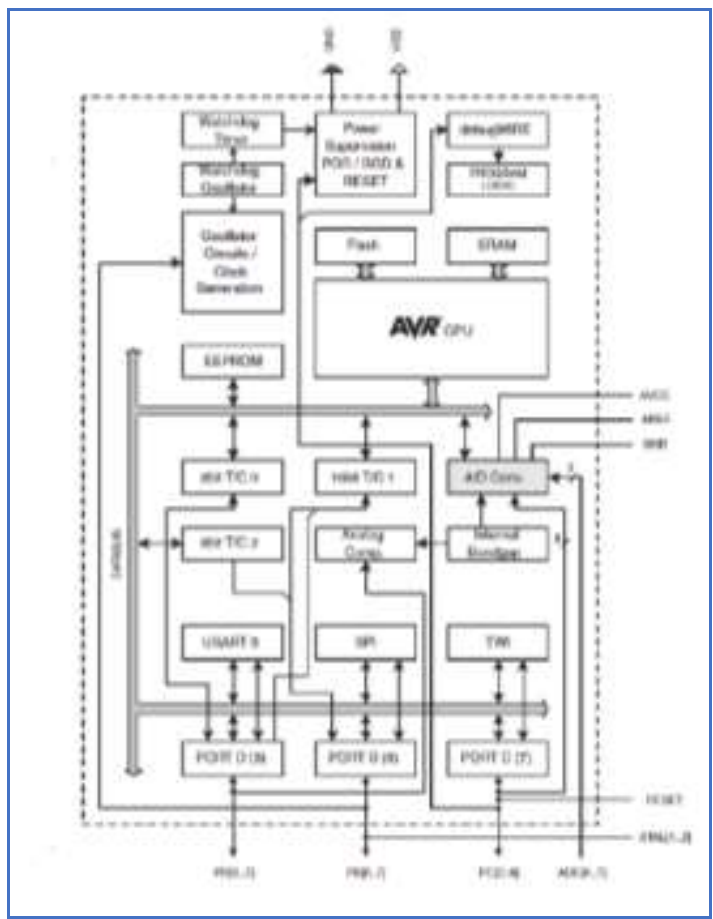

Gambar 2. Arsitektur ATMega-328

\section{2 Sensor MQ-2}

Gas Sensor (MQ-2) adalah sensor yang berguna untuk mendeteksi kebocoran gas baik pada rumah maupun industri. Sensor ini sangat cocok untuk mendeteksi $\mathrm{H} 2$, LPG, CH4, CO, Alkohol, Asap atau Propane. Karena sensitivitasnya yang tinggi dan waktu respon yang cepat, pengukuran dapat dilakukan dengan cepat 
[15], [16]. Sensor gas MQ-2 (Gambar 3) juga dikenal sebagai chemiresistor. Sensor berisi bahan penginderaan yang resistensi berubah ketika terjadi kontak dengan gas. Perubahan nilai resistansi inilah yang digunakan untuk mendeteksi gas [17].

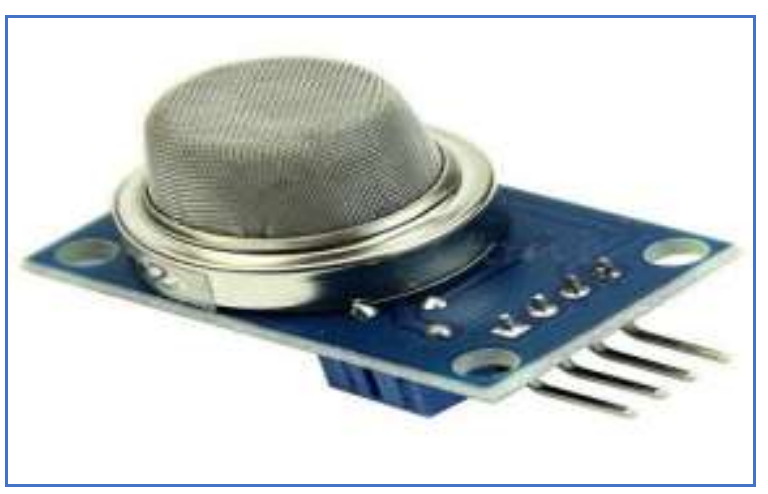

Gambar 3. Gas Sensor MQ-2

\section{3 Modul GSM SIM800L}

Modul SIM800L GSM / GPRS adalah modem GSM miniatur, yang dapat diintegrasikan ke dalam sejumlah besar proyek IoT. Dengan modul ini, hampir semua hal yang dapat dilakukan oleh ponsel biasa; pesan teks SMS, melakukan atau menerima panggilan telepon, menghubungkan ke internet melalui GPRS, TCP / IP, dan banyak lagi. Selain itu, modul ini mendukung jaringan GSM / GPRS quad-band, yang berarti cukup banyak digunakan di seluruh dunia [18]. Tampak pada Gambar 4, Modul SIM800L ini Menggunakan IC Chip SIM800, bekerja pada frequensi jaringan GSM yaitu QuadBand (850/900/1800/1900Mhz) Konektifitas class 1 (1W) pada DCS 1800 dan PCS 1900GPRS, sedangkan pada class 4 (2W) pada GSM 850 dan EGSM 900.

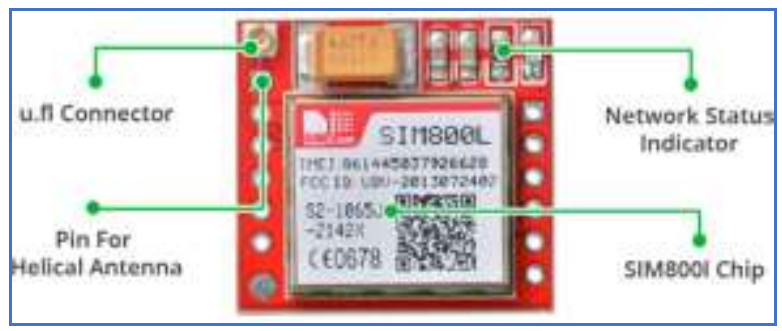

Gambar 4. Modul GSM SIM800L

Flow control sangat penting untuk komunikasi yang benar antara mesin GSM dan DTE. Karena dalam kasus seperti panggilan data atau faks, perangkat pengirim mentransfer data lebih cepat daripada pihak penerima untuk siap menerima. Pada dasarnya ada dua pendekatan untuk mencapai flow control data yaitu flow control perangkat lunak dan flow control perangkat keras. Seri SIM800 mendukung kedua jenis flow control [19]. Terdapat Led pada modul yang berfungsi sebagai indikator. Apabila pada modul terhubung dengan jaringan GSM maka LED akan berkedip perlahan, akan tetapi apabila tidak ada sinyal maka LED akan berkedip cepat. Seri SIM800 menggunakan port TTL serial port, sehingga dapat langsung diakses menggunakan mikrokontroler tanpa perlu memerlukan MAX232.

\section{Hasil dan Pembahasan}

Semua langkah yang dilakukan berikutnya adalah mengimplementasikan 
rancangan sebagaimana dijelaskan dalam diagram rancangan mekanik.

\section{1 Perancangan Mekanik}

Dalam perancangan mekanik alat pendeteksi kebocoran gas menggunakan kabel jumper agar rangkaian saling berhubungan, secara keseluruhan. Sensor Gas MQ-2 VCC, GND, dan A0 dihubungkan dengan Arduino memalui port 5V, GND, dan A0 sebagaimana terlihat di Gambar 5.

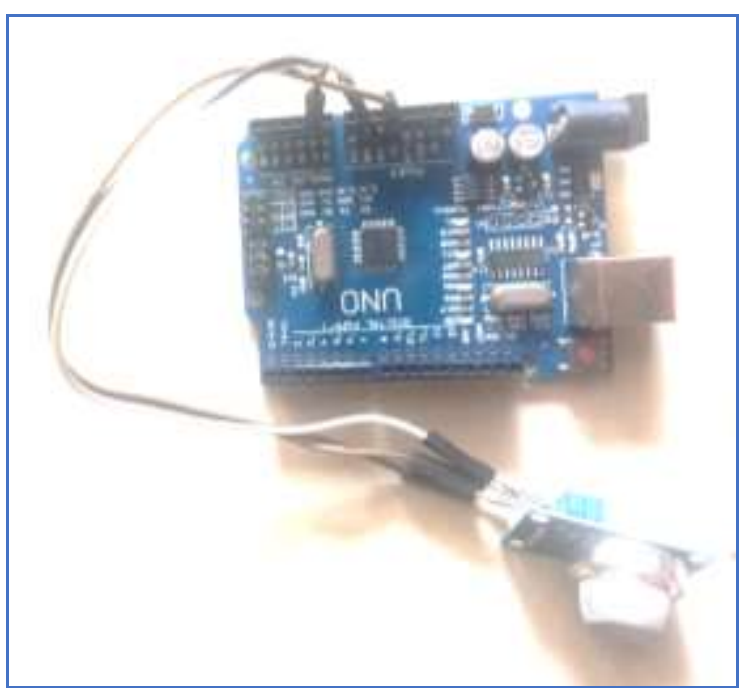

Gambar 5. Rangkaian Arduino dengan

$$
\text { Sensor MQ-2 }
$$

Setelah terhubung, lihat Gambar 6, kemudian Relay port VCC, GND, IN1 dihubungkan dengan Arduino memalui port 5V,GND, A2. Relay ini berfungsi untuk memutuskan ataupun menyambungkan daya listrik pada saat terdeteksi gas.

Selanjutnya Stepdown converter dihubungkan dengan power supply $9 \mathrm{~V}$ dengan cara parallel dan keluaran dari stepdown converter dihubungkan dengan modul GSM SIM800L melalui port VCC dan GND, lihat Gambar 7. Stepdown berfungsi untuk menurunkan tegangan yang dikeluarkan power supply 9V di convert menjadi $4.1 \mathrm{~V}$, bertujuan karena tegangan yang diperlukan untuk mengoperasikan SIM800L adalah 3.4V 4.2 VDC.

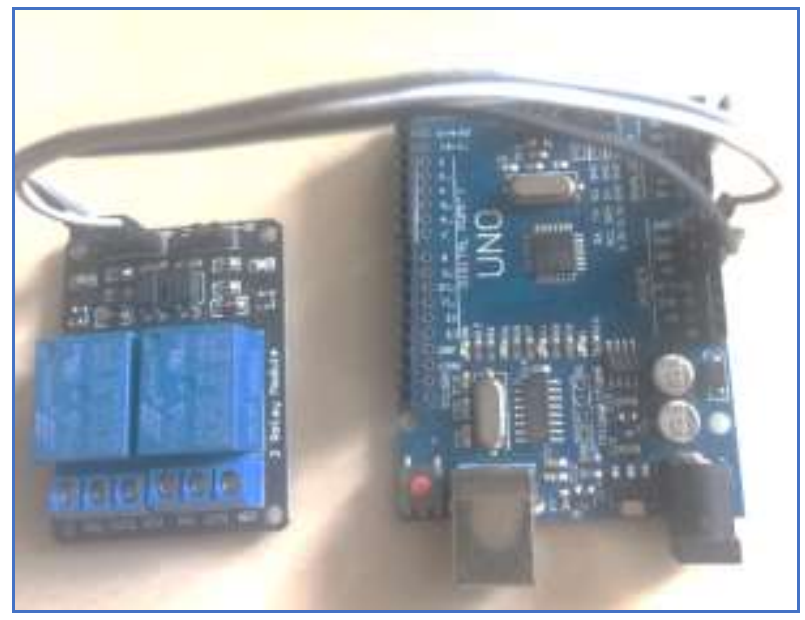

Gambar 6. Rangkaian Arduino dengan Relay

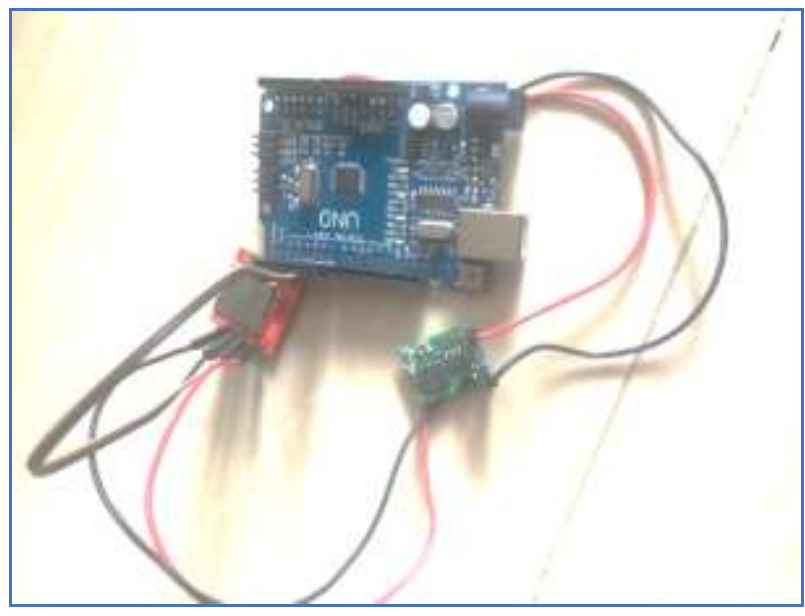

Gambar 7. Rangkaian Arduino, SIM800L, dan Stepdown Converter

Selanjutnya SIM800L RXD dan RTD dihubungkan ke Arduino melalui port Digital 7 dan 6. Setelah semua rangkaian 
terbuhung dengan benarnya Arduino diberi daya 9V dengan power supply sebagaimana terlihat pada Gambar 8.

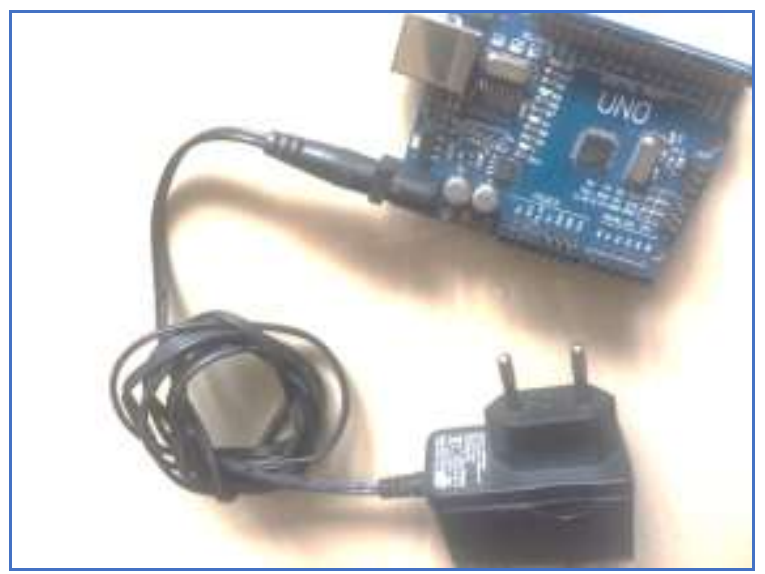

Gambar 8. Rangkaian adaptor dengan arduino

\section{2 Perancangan Perangkat Lunak}

Dalam perancangan perangkat lunak ini kami menggunakan metode pengembangan prototype, yang fokus pada esensi fungsional. Oleh karena itu secara teknis bertujuan untuk mengoperasikan alat pendeteksi gas agar bisa bekerja sebagaimana yang diharapkan, adapun kode-kode program yang sesuai dengan metode perancangan untuk menjalankan perangkat ini dapat dilihat dalam pembahasan di bawah.

Ketika rangkaian Arduino dinyalakan selanjutnya hal pertama yang dilakukan rangkaian adalah mengalamatkan relay sebagai keluaran dari Arduino sebagaimana terlihat pada Gambar 9. selanjutnya Arduino mengecek status dari SIM800L, jika status SIM800L dalam kondisi berfungsi dan sinyal sudah dimasuk, selanjutnya SIM800L mengirim
SMS ke nomor telepon untuk memberikan laporan bahwa rangkaian gas menyala.

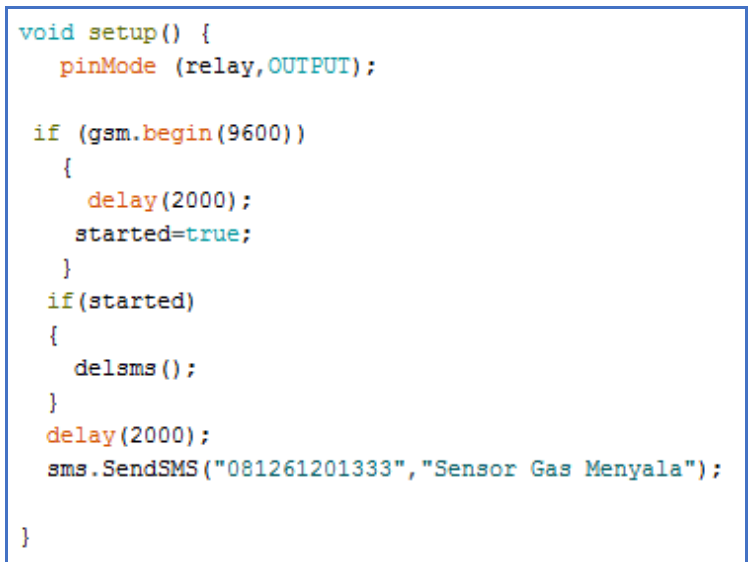

Gambar 9. Kode program awal dinyalakan

Selanjutnya ketika sensor gas mendeteksi gas LPG kondisi relay tetap low atau tidak diberi tegangan sampai batas yang ditentukan yaitu ketika analogread (0) melewati nilai val melebihi dari 50, lihat Gambar 10 di bawah.

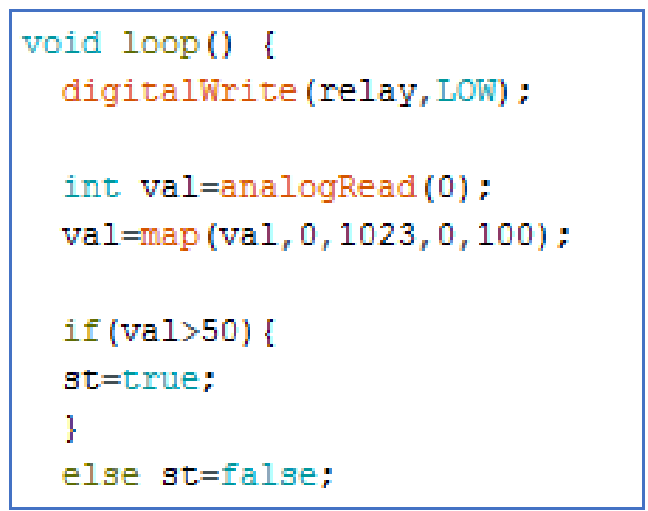

Gambar 10. Kode sensor mendeteksi Gas

Ketika kadar gas melebihi batas yang ditentukan dan sensor dalam status HIGH (diberi tegangan 5VDC) maka relay juga akan diberi tegangan 5VDC sehingga relay berpindah dari posisi normal open ke normal close dan memerintahkan mengirim SMS laporan kenomor telepon yang sudah diprogram dengan nilai 
konsentrasi yang di tangkap oleh sensor sebagaimana ditunjukkan Gambar 11.

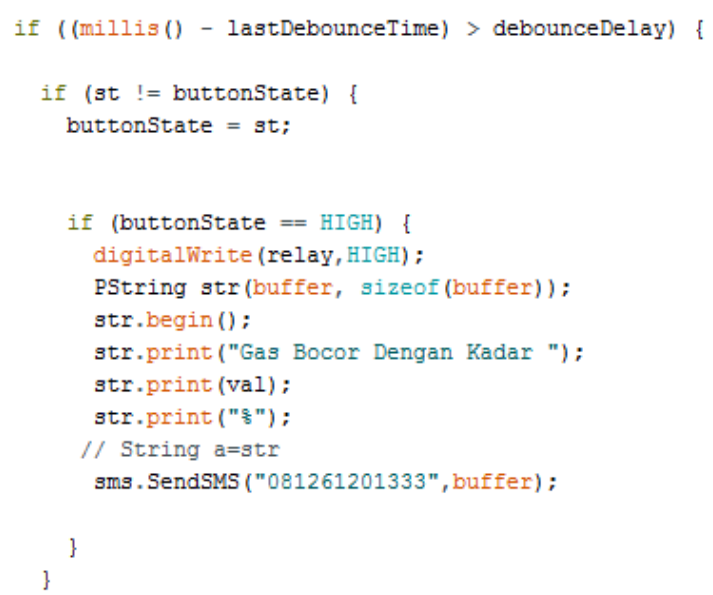

Gambar 11. Kode sensor melebihi batas kadar

Selanjutnya, untuk rancangan laporan kadar gas yang terdeteksi sensor. Gambar 12 adalah perintah Arduino untuk memberikan laporan secara langsung tanpa adanya gas yang terdeteksi oleh sensor, ini bertujuan untuk mengetahui apakah Arduino masih tetap beroperasi atau mengalami gangguan, dan dalam koding tersebut, Arduino hanya membaca isi SMS hanya dengan kata "lapor" maka SIM800L akan membalas secara otomatis isi pesan tersebut.

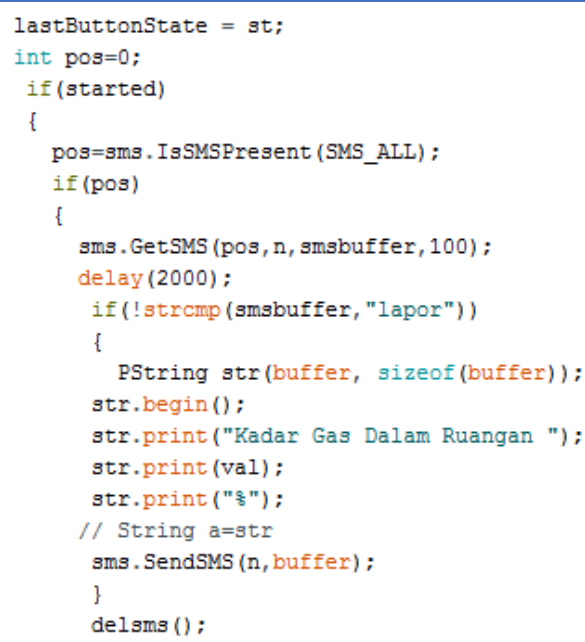

Gambar 12. Kode Permintaan status kadar gas

\section{3 Pengujian}

Pertama, pengujian sensor. Pada pengujian sensor, pengambilan data dilakukan dengan cara menyemprotkan gas dari sebuah korek api gas pada jarak 2 $\mathrm{cm}$ dengan lama waktu penyemprotan yang telah ditentukan. Penggunaan korek api (dilakukan karena cairan yang terdapat dalam korek api adalah sama dengan kandungannya isi dari tabung gas LPG yaitu cairan Butana). Pada rangkaian sensor harus diberikan tegangan sebesar 5 Volt sebagai Vcc dan tegangan heater pada sensor gas. Berikut ini adalah gambar riil dan Tabel 2. yang merupakan hasil pengujian: 
Tabel 2. Data Hasil Pengujian Sensor Gas Mq-2

\begin{tabular}{ccc}
\hline $\begin{array}{c}\text { Tegangan } \\
\text { Input } \\
\text { (Volt) }\end{array}$ & $\begin{array}{c}\text { Lama } \\
\text { Penyemprotan } \\
\text { (detik) }\end{array}$ & $\begin{array}{c}\text { Tegangan } \\
\text { Output } \\
\text { (Volt) }\end{array}$ \\
\hline $\mathbf{4 , 8 5}$ & 2 & 0,26 \\
\hline $\mathbf{4 , 8 5}$ & 4 & 1,82 \\
\hline $\mathbf{4 , 8 5}$ & 6 & 2,44 \\
\hline $\mathbf{4 , 8 5}$ & 8 & 2,68 \\
\hline $\mathbf{4 , 8 5}$ & 10 & 3,03 \\
\hline $\mathbf{4 , 8 5}$ & 12 & 3,24 \\
\hline $\mathbf{4 , 8 5}$ & 14 & 3,56 \\
\hline $\mathbf{4 , 8 5}$ & 16 & 3,91 \\
\hline $\mathbf{4 , 8 5}$ & 18 & 4,27 \\
\hline $\mathbf{4 , 8 5}$ & 20 & 4,55 \\
\hline
\end{tabular}

Hasil dari pengujian sensor gas LPG sesuai dengan harapan. Hasil rangkaian sensor tegangan pada Tabel 2 memiliki kelinieran yang sangat baik. Hasil dari sensor tegangan ini berupa tegangan DC dan sudah disearahkan untuk dapat digunakan sebagai input dari ADC mikrokontroler.

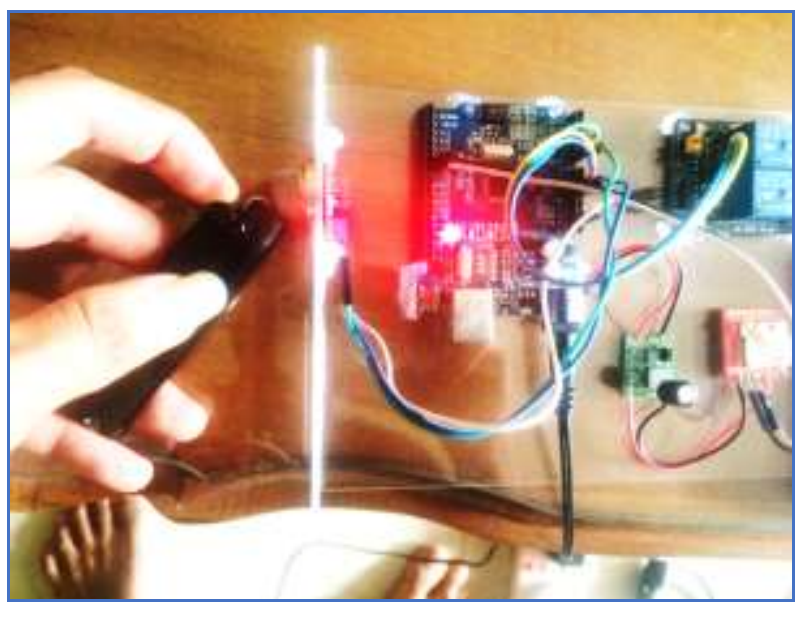

Gambar 13. Pengujian Gas MQ-2

Pada Gambar 13 menunjukkan proses pengujian sensor gas yang diberikan gas butana dari korek api gas untuk menguji fungsional dari sensor dan keseluruahan alat tersebut. Kemudian sistem akan mengirim SMS dari SIM800L yang menyatakan ada kadar gas terdeteksi oleh sensor dan kemudian relay mematikan alat listrik di rumah tersebut.

Kedua, pengujian menyeluruh. Pemasangan sensor gas LPG diletakkan pada dinding dalam lemari tabung gas LPG $3 \mathrm{~kg}$ atau $12 \mathrm{~kg}$. Pada pengujian ini, dengan skenario melubangi selang gas, sistem berfungsi dengan baik. Alat mendeteksi adanya gas LPG dan langsung mengaktifkan Relay dan mengirim laporan berupa SMS kepada pengguna yang berisi presentasi gas yang terdeteksi oleh sensor.

Tabel 3. Data Hasil Pengujian Menyeluruh

\begin{tabular}{|c|c|c|c|}
\hline No. & $\begin{array}{l}\text { Tegangan } \\
\text { Output } \\
\text { Sensor } \\
\text { (Volt) }\end{array}$ & $\begin{array}{l}\text { Waktu } \\
\text { yang } \\
\text { dibutuhkan } \\
\text { mengirim } \\
\text { SMS } \\
\text { (detik) }\end{array}$ & $\begin{array}{l}\text { Waktu } \\
\text { yang } \\
\text { dibutuhkan } \\
\text { relay off }\end{array}$ \\
\hline 1. & 0,26 & - & - \\
\hline 2. & 1,82 & - & - \\
\hline 3. & 2,44 & 2 & 2 \\
\hline 4. & 2,68 & 1,85 & 1,85 \\
\hline 5. & 3,03 & 1,52 & 1,50 \\
\hline 6. & 3,24 & 1,25 & 1,25 \\
\hline 7. & 3,56 & 0.59 & 0.59 \\
\hline 8. & 3,91 & 0.46 & 0.46 \\
\hline 9. & 4,27 & 0.25 & 0.25 \\
\hline 10. & 4,55 & 0.15 & 0.15 \\
\hline
\end{tabular}

Hasil pengujian yang ditunjukkan pada Tabel 3 merupakan hasil pengujian 
kebocoran pada area yang disimulasikan dengan cara melubangi dengan jarum di area ujung selang yang disambungkan dengan regulator sehingga terjadi kebocoran gas LPG. Hasil pengujian menunjukkan waktu yang dibutuhkan SIM800L untuk mengirim laporan dan mematikan relay. Dari sepuluh kali percobaan yang dilakukan, berdasarkan data waktu yang kami dapatkan, maka tidak ada perbedaan yang signifikan respon yang diberikan sistem, dengan percobaan yang dilakukan sebelumnya secara parsial.

Gambar 14 merupakan implementasi rangkaian terhadap tabung gas pada ruangan atau lemari gas yang di uji, gambar tersebut memberikan informasi bahwa sensor mendeteksi gas LPG dengan kadar 58\% dan menandakan bahwa gas melebihi batas wajar dalam ruangan atau area tesebut, atau bisa disimpulkan bahwa gas mengalami kebocoran atau selang regulator mengalami kebocoran.

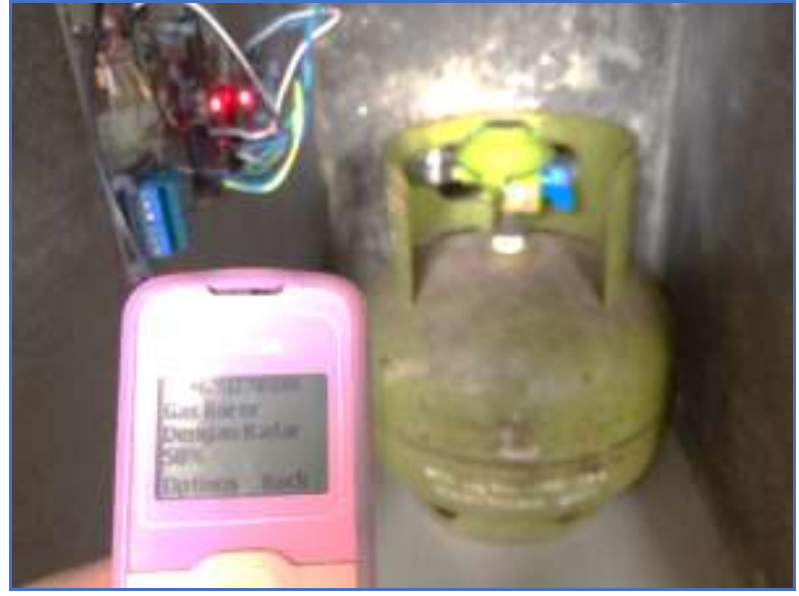

Gambar 14. Pengujian menyeluruh

Berikutnya pada Tabel 4 adalah konversi tegangan sensor kedalam bentuk data persentasi untuk mengirimkan SMS laporan. Dari hasil sepuluh kali percobaan tersebut artinya semakin kadar gas tinggi maka akan berpengaruh pada tegangan output sensor yang pada akhirnya menjadi triger respon SMS.

Tabel 4. Konversi Volt Tegangan Ke Prosentase

\begin{tabular}{c|c|c}
\hline No & $\begin{array}{c}\text { Tegangan output } \\
\text { sensor (volt) }\end{array}$ & $\begin{array}{c}\text { Hasil konversi } \\
\text { ke angka persen } \\
(\%)\end{array}$ \\
\hline $\mathbf{1}$ & $0.26-1.81$ & $0-13$ \\
\hline $\mathbf{2}$ & $1.82-2.43$ & $14-50$ \\
\hline $\mathbf{3}$ & $2.44-2.67$ & $51-54$ \\
\hline $\mathbf{4}$ & $2.68-3.02$ & $55-61$ \\
\hline $\mathbf{5}$ & $3.03-3.23$ & $62-65$ \\
\hline $\mathbf{6}$ & $3.24-3.55$ & $66-74$ \\
\hline $\mathbf{7}$ & $3.56-3.90$ & $75-79$ \\
\hline $\mathbf{8}$ & $3.91-4.26$ & $80-86$ \\
\hline $\mathbf{9}$ & $4.27-4.54$ & $87-94$ \\
\hline $\mathbf{1 0}$ & $4.55-4.85$ & $95-100$ \\
\hline
\end{tabular}




\section{SimpUlan}

Kesimpulan harus mengindikasikan secara jelas hasil penelitian yang diperoleh, kelebihan dan kekurangannya.

\section{1 Simpulan}

Dalam pendeteksian kebocoran gas LPG, ada titik kebocoran yang menjadi prioritas, sehingga semakin besar tegangan output sensor gas yang bocor itu keluar maka semakin cepat waktu yang dibutuhkan SIM800L untuk mengirim laporan dan mematikan relay.

Kemampuan alat dalam mendeteksi kebocoran gas dapat bekerja dengan cara diletakkan didekat tabung gas dan apabila sensor mendetekdi kebocoran gas dari tabung ataupun selang regulator gas, maka sensor akan aktif dan relay berubah menjadi mati secara otomatis, kemudian SIM800L akan mengirim laporan kepada user melalui SMS ke nomor telepon yang sudah disimpan oleh sistem untuk memberi laporan bahwa sensor gas mendeteksi gas.

\section{2 Saran}

Sebagai saran untuk penelitian lanjutan dapat ditambahkan display sebagai media output status kebocoran gas. Selain itu dapat ditambahkan sebuah alarm bunyi sebagai tambahan dari sistem SMS yang sudah ada.

\section{Daftar Pustaka}

[1] National Gas Company,

"Characteristics of LPG,"

https://nationalgasco.net, 2019.

https://nationalgasco.net/characteris tics-of-lpg/ (accessed Sep. 18, 2019).

[2] Sekretariat Kabinet, "Tahun 2018, Pemerintah Distribusikan 25.000

Paket Konventer Kit LPG Untuk

Nelayan Kecil,"

https://setkab.go.id, Jakarta, Feb. 05, 2018.

[3] Pertamina, "Polri : Kecelakaan Elpiji Diakibatkan oleh Kebocoran Gas," Media Pertamina, Jakarta, Jul. 2010.

[4] Kompas, "Rumah Tinggal Terbakar Akibat Regulator Tabung Gas Bocor," Kompas.com, 2019. https://megapolitan.kompas.com/rea d/2019/09/15/12451621/rumahtinggal-terbakar-akibat-regulatortabung-gas-bocor (accessed Sep. 18, 2019).

[5] M. M. Hasan Syukur, ST, "Penggunaan Liquified Petroleum Gases ( Lpg )," Forum Teknol., vol. 01, no. 2, pp. 1-14, 2011, [Online]. Available:

http://pusdiklatmigas.esdm.go.id/ne w/pusdiklatmigas/file/t2-_LPG_--- 
_M_hasan_Syukur.pdf.

[6] F. N. Arifenie, "Pertamina klaim kecelakaan tabung gas elpiji turun," https://industri.kontan.co.id/, Jakarta, 2011.

[7] S. T. Apeh, K. B. Erameh, and U. Iruansi, "Design and Development of Kitchen Gas Leakage Detection and Automatic Gas Shut off System," J. Emerg. Trends Eng. Appl. Sci., vol. 5, no. 3, pp. $222-$ 228, 2014.

[8] P. Gour and B. Sonawane, "Gas leak Detection, Monitoring and Prevention," Int. J. Emerg. Technol. Adv. Eng., vol. 4, no. 7, pp. 466468, 2014.

[9] T. H. Mujawar, V. D. Bachuwar, M. S. Kasbe, A. D. Shaligram, and L. P. Deshmukh, "Design and Development of Lpg Gas Leakage Detection and," Solapur Univ. Res. J., vol. 4, no. 1, pp. 1-6, 2015.

[10] D. Ibrahim, Microcontroller Based Applied Digital Control. 2006.

[11] H. Andrianto, Belajar Cepat dan Pemrograman Android. Bandung: Informatika Bandung, 2017.

[12] M. Timothy J. Wilkinson, Scott B. Guthery, Ksheerabdhi Krishna, “USINGA HIGH LEVEL PROGRAMMING LANGUAGE WITH A MICROCONTROLLER,”
US 6,308,317 B1, 2019.

[13] B. W. Gunther Gridling, Introduction to Microcontrollers, 1.4. Vienna: Vienna University of Technology, 2007.

[14] S. Z. Nasir, "Introduction to ATmega328," https://www.theengineeringprojects .com, Gulberg, Sep. 18, 2019.

[15] B. B. L. Heyasa and V. R. K. R. Galarpe, "Preliminary Development and Testing of MicrocontrollerMQ2 Gas Sensorfor University Air Quality Monitoring," IOSR J. Electr. Electron. Eng., vol. 12, no. 03, pp. 47-53, 2017, doi: 10.9790/1676-1203034753.

[16] D. A. Himawan, Fadhil Puri. Sunarya, Unang. Nurmantris, "PERANCANGAN ALAT PENDETEKSI ASAP BERBASIS MIKROKONTOLLER," EProceeding Appl. Sci., vol. 3, no. 3, pp. 1963-1968, 2017.

[17] M. Y. Hariyawan, A. Gunawan, and E. H. Putra, "Wireless sensor network for forest fire detection," Telkomnika, vol. 11, no. 3, pp. 563574, 2013, doi:

10.12928/TELKOMNIKA.v11i3.10 56.

[18] S. Aliyu, A. Yusuf, U. Abdullahi, M. Hafiz, and L. A. Ajao, 
"Development of a low-cost GSM-

bluetooth home automation

system," Int. J. Intell. Syst. Appl.,

vol. 9, no. 8, pp. 41-50, 2017, doi:

10.5815/ijisa.2017.08.05.

[19] SIMCOM, SIM800 Series_AT

Command Manual_V1.09,1st ed.

Shanghai: SIMCOM, 2015.

[20] Fitria, Y. A. (2019). Visualization

of Data on Earthquake Prone

Areasfrom the Analysis of

Earthquake Data Vibrations. Test

Engineering \& Management, 5301-

5308.

[21] Fitria -, M. F. (2018). Teknologi

Informasi E-Complaint pada

Perguruan Tinggi. jurnal

Informatika Darmajaya, 116-123. 